\title{
Correction to: Optimal power allocation for CRN-NOMA systems with adaptive transmit power
}

\author{
Raed Alhamad $^{1} \mathbb{D} \cdot$ Hatem Boujemâa ${ }^{2}$
}

Published online: 13 May 2020

๑) Springer-Verlag London Ltd., part of Springer Nature 2020

\section{Correction to:}

Signal, Image and Video Processing https://doi.org/10.1007/s11760-020-01674-8

Unfortunately, the Acknowledgement section has been missed in the original publication of the article. The complete section is given below:

The sincere appreciation for the deanship of Scientific research at Saudi Electronic University for funding this research.

Publisher's Note Springer Nature remains neutral with regard to jurisdictional claims in published maps and institutional affiliations.

The original article can be found online at https://doi.org/10.1007/s11 760-020-01674-8.

Raed Alhamad

ralhamad@seu.edu.sa

Hatem Boujemâa

boujemaa.hatem@supcom.tn

1 Department of Computer Science, Saudi Electronic

University, Riyadh, Saudi Arabia

2 COSIM Lab, Tunis, Tunisia 